\title{
KORELASI KEPUASAN MENGHUNI DAN KARAKTERISTIK TEMPAT TINGGAL: STUDI META ANALISIS
}

\author{
Intan Rahmawati \\ Universitas Brawijaya, Malang \\ intanr@ub.ac.id
}

\begin{abstract}
Abstrak
Perkembangan kehidupan saat ini memperlihatkan perubahan yang luar biasa pada keadaan sosial termasuk salah satunya adalah pembuatan desain bangunan atau tempat tinggal. Para pendesain seringkali mencoba memberikan bentuk yang sesuai dengan perubahan lingkungan namun tidak cocok dengan keterbatasan yang dihadapi. Dari sinilah dapat terlihat bagaimana tempat tinggal dibuat yang juga tentunya akan memberikan pengaruh pada bentuk perilaku penghuninya. Berdasarkan peta penelitian diperoleh hasil bahwa kepuasan menghuni dipengaruhi oleh karakteristik tempat tinggal seperti pencahayaan, ukuran, jumlah serta keadaan ruang. Dari beragam penelitian tentang hal ini, tampak kurang kekonsistenan dalam hasil, sehingga dibutuhkan cara lain untuk mengkajinya yakni meta-analisis. Tujuan penelitian ini untuk mengkaji hasil-hasil penelitian yang telah dilakukan para peneliti di bidang arsitektur dan psikologi lingkungan, apakah karakteristik hunian secara konsisten berkaitan dengan kepuasan menghuni. Studi meta analisis menghasilkan karakteristik hunian memberikan kontribusi terhadap kepuasan menghuni.
\end{abstract}

Kata kunci : karakteristik tempat tinggal, kepuasan menghuni, meta-analisis

\begin{abstract}
Title: Correlation of Residential Satisfaction and Housing Characteristics: A Meta-Analysis

Development of life today shows remarkable changes in social circumstances including the one of which is design manufacture building or residence. The designers often try to give shape according to changes in the environment, but does not fit with the constraints faced. From this it can be seen how the shelter was made which would also be an impact on the behavior of its inhabitants, based on the map of the research results that inhabit satisfaction is influenced by characteristics of the dwelling, such as lighting, size, number and state of the room. From a variety of research on this, it seems less consistency in the results, so we need another way of studying the meta-analysis. The purpose of this study was to assess the results of research that has been done by researchers in the field of architecture and environmental psychology, that housing characteristics are consistently associated with satisfaction of inhabitants. The meta-analysis resulted in the housing characteristics contribute to inhabitants satisfaction.
\end{abstract}

Keywords: housing characteristics, residential satisfaction, meta-analysis

\section{Pendahuluan}

Saat ini kepuasan menghuni menjadi topik utama dalam kajian mengenai tempat tinggal. Rumah yang merupakan tempat tinggal merupakan elemen penting yang memberikan dampak pada kehidupan seseorang. Terminologi kepuasan penghuni merujuk pada kepuasan individu terhadap kondisi atau lingkungan tempat ia tinggal, yang tentunya memiliki konsep hubungan pada aspek 
kebutuhan, harapan, dan prestasi atau kemampuan menuju suatu goal (Amerigo \& Aragones, 1990).

Secara empiris, banyak kajian yang meneliti tentang fitur rumah yang memberikan dampak pada level kepuasan penghuninya. Beberapa peneliti memberikan hasil risetnya seperti kualitas lift, pencahayaan, sirkulasi udara, kepadatan, ukuran ruang, ketersediaan ruang hijau atau taman, dan sebagainya yang berkaitan dengan fitur tempat tinggal bahwa itu semua memiliki keterkaitan dengan kepuasan penghuni (Gomez-Jacinto \& Hombrados-Mendieta, 2002 ; Kaplan, 1985). Selain itu, Phillips dkk (2004) menambahkan faktor kebutuhan yang diperlukan oleh penghuni area tempat tinggal sehingga dapat terlihat tingkat kepuasannya. Misalnya saja infrastruktur seperti jalur transportasi (kereta, bis, angkutan umum, dsb) dan fasilitas yang dibutuhkan oleh komunitas seperti sekolah, bank, klinik, apotek, kantor pos, area bermain, dan sebagainya. Faktor kebutuhan ini menurutnya akan menimbulkan rasa nyaman pada penghuni.

Lebih lanjut, lingkungan tempat tinggal bukan hanya bentuk fisik dari elemen tempat tinggalnya saja, melainkan juga hal-hal lain yang ada di kelilingnya, yakni tetangga, karena seringkali tetangga dan relasi pertetanggaan yang terjadi akan memunculkan bentuk perilaku masing-masing individu yang berada di sekitarnya (Bond, 1993; Golant, 1984).

\section{Kajian Teori}

Phillips, Siu, Yeh \& Cheng (2004) menjelaskan tiga aspek yang membentuk kepuasan penghuni, yaitu:
1) Struktural

Aspek ini mengacu pada karakteristik fisik tempat tinggal, seperti pencahayaan, ukuran ruang, keberadaan taman, dan lain-lain.

2) Formal

Yang termasuk dalam domain ini adalah fasilitas umum yang memudahkan aktivitas komunitas, seperti penitipan anak, klinik, transportasi, toko, dan lain-lain.

3) Informal

Domain ini mengacu pada hal-hal yang mendukung keberadaan komunitas seperti tetangga, jumlah anggota keluarga, maupun kelompok-kelompok kecil dalam lingkungan tempat tinggal.

Kualitas tempat tinggal dapat dilihat dari ruangan, masa kepemilikian, struktur dalam perawatan dan norma pertetanggaan. Kutty (1999) mengidentifikasi beberapa indikator lain untuk melihat kualitas dari tempat tinggal, yakni struktur yang adekuat, kualitas pertetanggaan yg baik, keamanan lingkungan, fasilitas umum, dan terdapat akses untuk bekerja. Austin dkk (2002) dan Kaplan \& Kaplan (2003) menambahkan aspek yang paling utama untuk melihat kualitas dari tempat tinggal yaitu system pertetanggaannya, keamanan, dan kebersihan lingkungan. Morris dkk (1976) menyebutkan bahwa aspek tersebut dapat memunculkan adaptasi serta penyesuaian penghuninya.

Mowen (1995) membuat gambaran kepuasan penghuni sebagai rasio kualitas hunian yang ditempati dan kebutuhan, keinginan, serta harapan penghuninya. Rasio ini memberikan pengertian bahwa kepuasan tinggal dapat terwujud apabila kualitas yang ditempati sesuai dengan kebutuhan dan harapan penghuninya, sehingga bisa 
memberikan dampak positif bagi peningkatan kualitas hidupnya.

Dalam hal ini (kepuasan menghuni) dapat diterjemahkan sebagai sebuah proses kognitif penghuni pada lokasi hunian, mulai dari memperhatikan, merasakan, dan memproses informasi yang didapat atau dirasakan pada hunian tersebut, sehingga penghuni mampu memilai apakah sesuai dengan keinginan, kebutuhan dan harapannya. Keinginan, kebutuhan dan harapan tinggal yang dimaksud di dalamnya adalah hunian yang nyaman, sehat dan sesuai dengan fungsi rumah itu sendiri. Sehingga, kenyamanan tinggal merupakan produk dari rasa puas penghuni terhadap rumah yang ditempati.

Studi preferensi tentang perumahan dan kepuasan telah berusaha untuk mendefinisikan kriteria yang penting untuk mengevaluasi perumahan. Dillman dan Tremblay menemukan hubungan yang kuat antara tempat tinggal dengan empat norma rumah yang dikemukakan oleh Morris dan Winter (1978) dengan model housing adjustment-nya, yakni kepemilikan, ruang pribadi, struktur konvensional, dan tempat tinggal terpisah.

Stewart dan Mc.Known (1977) mengujinya dengan asumsi bahwa kepuasan menghuni memiliki posisi sebagai variable intervening diantara karakteristik keluarga atapun karakteristik tempat tinggal dan keinginan untuk mengubah perumahan. Mereka menunjukkan bahwa kepuasan dengan aspek yang berbeda dari perumahan dipengaruhi secara berbeda pula oleh karakteristik keluarga dan rumah yang saat ini ia tempati. McCray dan Day (1977) menemukan faktor social dan kondisi lingkungan di desa maupun di kota juga memberikan pengaruh pada kebiasaan dan pada gilirannya kepuasan menghuni suatu tempat akan dapat dilihat melalui lingkungannya secara holistik.

Rent (1973), pada studinya tentang keluarga yang berpenghasilan rendah di South Carolina, menganalisis tentang kepuasan menghuni, menemukan secara signifikan mengenai hubungan yang positif antara kepuasan menghuni dengan kepuasan bertetangga, status kepemilikan, tipe tempat tinggal, kepuasan dengan tetangga, dan kepuasan hidup secara umum.

Rogers dan Nikkel (1979) memberikan penilaian berbasis keluhan ruang perumahan dan biaya perumahan untuk menentukan dampak dari jumlah keluarga pada kepuasan perumahan. Kesimpulannya secara umum bahwa jumlah keluarga adalah variable penting untuk melihat kepuasan penghuni, dan jika jumlah keluarga meningkat maka kepuasan penghuni yang tinggal di perumahan multifamily (seperti rumah susun) akan menurun.

Dari studi di atas, peneliti memutuskan melakukan meta-analisis dengan variabel kepuasan menghuni dan karakteristik tempat tinggal. Selain bertujuan membuat kesimpulan dan mensitesakan beberapa studi yang memiliki penemuan beragam seperti yang telah dijelaskan sebelumnya, meta-analisis ini bertujuan untuk memberikan referensi tambahan untuk lebih menguatkan peranan karakteristik tempat tinggal pada kepuasan penghuninya.

\section{Metode Penelitian}

Pengumpulan data menggunakan data sekunder yang diakses melalui www.lib.ugm.ac.id, selain dari sumber tersebut, peneliti juga mencari koleksi 
penelitian primer di perpustakaan Fakultas Teknik UGM dengan kata kunci residential satisfaction dan housing characteristics. Data yang digunakan adalah jumlah subjek $(\mathrm{N})$, nilai korelasi $\mathrm{r}$ atau $\mathrm{F}$; skor rerata, koefisien reliabilitas, standar deviasi, karakteristik subjek penelitian, dan merupakan studi primer. Berdasarkan kriteria tersebut, peneliti mendapatkan 20 studi untuk kemudian dilakukan meta-analisis

\section{Langkah Studi Meta-Analisis}

Langkah-langkah yang dilakukan dalam analisis dan interpretasi data meliputi manajemen data dan penyandian. Data dikelompokkan berdasarkan tema tertentu, misalnya tipe rumah terhadap kepuasan penghuni, dengan membedakan jenis kelamin, ataupun tingkatan usia kemudian melakukan penyandian. Seperti tabel berikut

Tabel 1. Sumber jurnal yang digunakan untuk studi meta analisis

\begin{tabular}{|c|c|c|c|c|}
\hline No & Peneliti & Tahun & $\mathbf{N}$ & Subjek \\
\hline $\mathbf{1}$ & $\begin{array}{l}\text { Addokun Jagun, Diane R. Brown, } \\
\text { Norweeta G. Milburn \& Lawrence E. } \\
\text { Gary }\end{array}$ & 1990 & 1018 & orang kulit hitam \\
\hline 2 & $\begin{array}{l}\text { Katherine A Marx, Kesey L. Burke, BS } \\
\text { Jean M. Gaines, Barbara Resnick, John } \\
\text { M }\end{array}$ & 2011 & 300 & penghuni rumah baru \\
\hline 3 & Russel N. James & 2008 & 43360 & penghuni rumah sewa \\
\hline 4 & M. Abdul Mohit \& Nurul Nozyddah & 2011 & 250 & penghuni rumah \\
\hline 5 & $\begin{array}{l}\text { Sung Heui Cho, Tae Kyung Lee \& Jeong } \\
\text { Tai Kim }\end{array}$ & 2010 & 168 & penghuni apartemen \\
\hline 6 & $\begin{array}{l}\text { Karien Dekker, Sjoerd De Vos, Sako } \\
\text { Musterd \& Ronald Van Kempen }\end{array}$ & 2011 & 4756 & penghuni rumah \\
\hline 7 & $\begin{array}{l}\text { Zikri Muhammad, Katiman Rostam, } \\
\text { Yusliza MY }\end{array}$ & 2010 & 638 & penduduk \\
\hline 8 & Irit Sinai & 2000 & 492 & kepala rumah tangga \\
\hline 9 & C.C. M. Adriaanse & 2007 & 50592 & penghuni rumah \\
\hline 10 & Max Lu & 1999 & 55000 & penghuni rumah \\
\hline 11 & Russell N. James & 2007 & 5170 & penyewa rumah \\
\hline 12 & Eziyi O. Ibem \& Dalapo Amole & 2013 & 452 & penghuni rumah \\
\hline 13 & Russel N. James & 2008 & 1524 & lansia \\
\hline 14 & Willard Rodgers & 1980 & 2164 & penduduk \\
\hline 15 & $\begin{array}{l}\text { Sam Tsemberis, E. Sally Rogers, Eleni } \\
\text { Rodis, Patricia Dushuttle \& Vicki Skryha }\end{array}$ & 2003 & 300 & penghuni rumah \\
\hline 16 & Ling-Hin Li & 2009 & 267 & penghuni rumah \\
\hline 17 & $\begin{array}{l}\text { Pinar Dicn, Emine Ozbilen \& Mehmet B } \\
\text { Bilir }\end{array}$ & 2013 & 80 & penghuni rumah \\
\hline 18 & $\begin{array}{l}\text { Geoffrey Nelso, G. Brent Hall, Richard } \\
\text { W. Bowers }\end{array}$ & 1998 & 107 & survivor \\
\hline 19 & Omer Lutfi Kellekci \& Lale Berkoz & 2006 & 401 & pendatang \\
\hline 20 & $\begin{array}{l}\text { Philip Baiden, Godwin Arku, Issae } \\
\text { Luginaah }\end{array}$ & 2011 & 562 & penghuni rumah \\
\hline
\end{tabular}

Sumber: Hasil analisis, 2015.

Setelah data dikelompokkan dan peneliti mentransformasikan data yang dilakukan penyandian untuk mengandung nilai $\mathrm{F}, \mathrm{t}$ dan $\mathrm{d}$ ke dalam mempermudah dalam pengolahan data, nilai $\mathrm{r}$ agar dapat dibandingkan. 
Tabel 2. Karakteristik korelasi setelah dilakukan transformasi

\begin{tabular}{cclr}
\hline No & $\mathbf{N}$ & \multicolumn{1}{c}{ Subjek } & $\mathbf{r}_{\mathbf{X Y}}$ \\
\hline $\mathbf{1}$ & 1018 & orang kulit hitam & 0.458 \\
$\mathbf{2}$ & 300 & penghuni rumah baru & 0.067 \\
$\mathbf{3}$ & 43360 & penghuni rumah sewa & 0.744 \\
$\mathbf{4}$ & 250 & penghuni rumah & 1.000 \\
$\mathbf{5}$ & 168 & penghuni apartemen & 0.075 \\
$\mathbf{6}$ & 4756 & penghuni rumah & 0.490 \\
$\mathbf{7}$ & 638 & penduduk & 0.009 \\
$\mathbf{8}$ & 492 & kepala rumah tangga & 0.133 \\
$\mathbf{9}$ & 50592 & penghuni rumah & 0.040 \\
$\mathbf{1 0}$ & 55000 & penghuni rumah & 0.200 \\
$\mathbf{1 1}$ & 5170 & penyewa rumah & 0.670 \\
$\mathbf{1 2}$ & 452 & penghuni rumah & 0.182 \\
$\mathbf{1 3}$ & 1524 & lansia & 0.094 \\
$\mathbf{1 4}$ & 2164 & penduduk & 0.046 \\
$\mathbf{1 5}$ & 300 & penghuni rumah & 0.077 \\
$\mathbf{1 6}$ & 267 & penghuni rumah & 0.009 \\
$\mathbf{1 7}$ & 80 & penghuni rumah & 0.495 \\
$\mathbf{1 8}$ & 107 & survivor & 0.269 \\
$\mathbf{1 9}$ & 401 & pendatang & 0.088 \\
$\mathbf{2 0}$ & 562 & penghuni rumah & 0.346 \\
Total & 167601 & & 5.492 \\
rerata & 8380.05 & & 0.2746 \\
STD & 17946.14 & & \\
\hline
\end{tabular}

Sumber: Hasil analisis, 2015.

Setelah mengubah menjadi nilai r, Mencari rerata korelasi populasi $(\breve{r})$ maka langkah berikutnya adalah dengan rumus melakukan Bare-bone meta analysis yaitu melakukan koreksi terhadap kesalahan dalam pengambilan sampel dengan menghitung rerata korelasi populasi dan melakukan koreksi terhadap kesalahan pengukuran yang dilakukan dengan melakukan estimasi korelasi berdasarkan data koefisien reliabilitas dari instrumen yang digunakan.

Koreksi kesalahan dalam pengambilan sampel (Bare-bone Meta Analysis) dilakukan melalui langkah-langkah sebagai berikut:

$$
\check{r}=\frac{\sum\left(N_{x} r_{x y}\right)}{\sum N}
$$

dari adalah hasil korelasi antara variable $X$ dan $Y$ (residential satisfaction dengan housing characteristic) pada studi i; sedangkan $\mathrm{Ni}$ adalah jumlah sampel pada studi i. Langkah berikutnya adalah mengubah nilai ri atau rxy pada masing-masing studi untuk mendapatkan rerata korelasi populasi, seperti disajikan dalam Tabel 3.

Tabel 3. Koreksi kesalahan sampling

\begin{tabular}{cclrr}
\hline No & $\mathbf{N}$ & \multicolumn{1}{c}{ Subjek } & $\mathbf{r}_{\mathbf{X Y}}$ & $\mathbf{N}_{\mathbf{X}} \mathbf{R}_{\mathbf{X Y}}$ \\
\hline $\mathbf{1}$ & 1018 & orang kulit hitam & 0.458 & 466.244 \\
$\mathbf{2}$ & 300 & penghuni rumah baru & 0.067 & 20.1 \\
$\mathbf{3}$ & 43360 & penghuni rumah sewa & 0.744 & 32259.84 \\
$\mathbf{4}$ & 250 & penghuni rumah & 1.000 & 250 \\
$\mathbf{5}$ & 168 & penghuni apartemen & 0.075 & 12.6 \\
$\mathbf{6}$ & 4756 & penghuni rumah & 0.490 & 2330.44 \\
\hline
\end{tabular}




\begin{tabular}{cclrr}
\hline No & $\mathbf{N}$ & \multicolumn{1}{c}{ Subjek } & $\mathbf{r}_{\mathbf{X Y}}$ & \multicolumn{1}{c}{$\mathbf{N}_{\mathbf{X}} \mathbf{R}_{\mathbf{X Y}}$} \\
\hline $\mathbf{7}$ & 638 & penduduk & 0.009 & 5.742 \\
$\mathbf{8}$ & 492 & kepala rumah tangga & 0.133 & 65.436 \\
$\mathbf{9}$ & 50592 & penghuni rumah & 0.040 & 2023.68 \\
$\mathbf{1 0}$ & 55000 & penghuni rumah & 0.200 & 11000 \\
$\mathbf{1 1}$ & 5170 & penyewa rumah & 0.670 & 3463.9 \\
$\mathbf{1 2}$ & 452 & penghuni rumah & 0.182 & 82.264 \\
$\mathbf{1 3}$ & 1524 & Lansia & 0.094 & 143.256 \\
$\mathbf{1 4}$ & 2164 & penduduk & 0.046 & 99.544 \\
$\mathbf{1 5}$ & 300 & penghuni rumah & 0.077 & 23.1 \\
$\mathbf{1 6}$ & 267 & penghuni rumah & 0.009 & 2.403 \\
$\mathbf{1 7}$ & 80 & penghuni rumah & 0.495 & 39.6 \\
$\mathbf{1 8}$ & 107 & Survivor & 0.269 & 28.783 \\
$\mathbf{1 9}$ & 401 & pendatang & 0.088 & 35.288 \\
$\mathbf{2 0}$ & 562 & penghuni rumah & 0.346 & 194.452 \\
Total & 167601 & & 5.492 & 52546.67 \\
rerata & 8380.05 & & 0.2746 & 0.313522 \\
STD & 17946.14 & & & \\
\hline
\end{tabular}

Sumber: Hasil analisis, 2015

Berdasarkan lembar kerja yang Mencari varians rxy

tercantum dalam table 3 di atas, dapat Langkah selanjutnya setelah dihitung rerata korelasi populasi setelah mengetahui rerata korelasi populasi dikoreksi dengan jumlah sampel adalah menghitung varians korelasi. 167601. Adapun hasilnya adalah Adapun hasilnya disajikan dalam tabel 0.313522 , jika dibulatkan menjadi 4. Varians $\mathbf{r}_{\mathbf{X Y}}$ 0.314 .

Tabel 4. Varians rXY

\begin{tabular}{|c|c|c|c|c|c|c|c|}
\hline No & $\mathbf{N}$ & Subjek & $\mathbf{r}_{\mathbf{X Y}}$ & NXRXY & rxy-r & $(\mathbf{r x y}-\mathrm{r})^{\wedge} 2$ & $\mathrm{~N}(\mathrm{rxy}-\mathrm{r})^{\wedge} 2$ \\
\hline 1 & 1018 & orang kulit hitam & 0.458 & 466.244 & 0.144 & 0.0209 & 21.24949745 \\
\hline 2 & 300 & $\begin{array}{l}\text { penghuni rumah } \\
\text { baru }\end{array}$ & 0.067 & 20.1 & -0.247 & 0.0608 & 18.23199185 \\
\hline 3 & 43360 & $\begin{array}{l}\text { penghuni rumah } \\
\text { sewa }\end{array}$ & 0.744 & 32259.84 & 0.430 & 0.1853 & 8035.08246 \\
\hline 4 & 250 & penghuni rumah & 1.000 & 250 & 0.686 & 0.4713 & 117.8128651 \\
\hline 5 & 168 & $\begin{array}{l}\text { penghuni } \\
\text { apartemen }\end{array}$ & 0.075 & 12.6 & -0.239 & 0.0569 & 9.558015157 \\
\hline 6 & 4756 & penghuni rumah & 0.490 & 2330.44 & 0.176 & 0.0311 & 148.1224543 \\
\hline 7 & 638 & Penduduk & 0.009 & 5.742 & -0.305 & 0.0927 & 59.16423299 \\
\hline 8 & 492 & $\begin{array}{l}\text { kepala rumah } \\
\text { tangga }\end{array}$ & 0.133 & 65.436 & -0.181 & 0.0326 & 16.03346625 \\
\hline 9 & 50592 & penghuni rumah & 0.040 & 2023.68 & -0.274 & 0.0748 & 3785.016051 \\
\hline 10 & 55000 & penghuni rumah & 0.200 & 11000 & -0.114 & 0.0129 & 708.8037573 \\
\hline 11 & 5170 & penyewa rumah & 0.670 & 3463.9 & 0.356 & 0.1271 & 656.9842708 \\
\hline 12 & 452 & penghuni rumah & 0.182 & 82.264 & -0.132 & 0.0173 & 7.818763055 \\
\hline 13 & 1524 & Lansia & 0.094 & 143.256 & -0.220 & 0.0482 & 73.44170509 \\
\hline 14 & 2164 & Penduduk & 0.046 & 99.544 & -0.268 & 0.0716 & 154.8736887 \\
\hline 15 & 300 & penghuni rumah & 0.077 & 23.1 & -0.237 & 0.0559 & 16.7828573 \\
\hline 16 & 267 & penghuni rumah & 0.009 & 2.403 & -0.305 & 0.0927 & 24.7599533 \\
\hline 17 & 80 & penghuni rumah & 0.495 & 39.6 & 0.181 & 0.0329 & 2.63472881 \\
\hline 18 & 107 & Survivor & 0.269 & 28.783 & -0.045 & 0.0020 & 0.21210036 \\
\hline 19 & 401 & Pendatang & 0.088 & 35.288 & -0.226 & 0.0509 & 20.39500609 \\
\hline 20 & 562 & penghuni rumah & 0.346 & 194.452 & 0.032 & 0.0011 & 0.592793587 \\
\hline Total & 167601 & & 5.492 & 52546.67 & & & 13877.57066 \\
\hline rerata & 8380.05 & & 0.2746 & 0.313522 & & & 0.08280124 \\
\hline STD & 17946.14 & & & & & & \\
\hline
\end{tabular}


Hasil perhitungan di atas menunjukkan bahwa varians $r_{x y}$ atau $\boldsymbol{o}^{2} \mathbf{r}$ sebesar 0.08280124, jika dibulatkan menjadi 0.083 .

Mencari varians kesalahan pengambilan sampel $\left(\sigma^{2} e\right)$

Varians $r_{x y}$ sebesar 0.083 merupakan campuran antara dua hal, yaitu variasi dalam korelasi populasi dan variasi dalam korelasi sampel yang disebabkan oleh kesalahan sampling. Estimasi varians dalam korelasi populasi dapat diperoleh dengan mengoreksi varians $\sigma^{2} \mathrm{r}$ yang teramati untuk kesalahan sampling (Hunter \& Schmidt, 2004). Adapun rumusnya adalah:

$$
\sigma^{2} \mathbf{e}=\frac{\left(1-r^{2}\right)^{2}}{(\mathrm{~N}-1)}
$$

Hasil yang di peorleh adalah sebesar 0,000097

\section{Estimasi varians korelasi populasi $\left(\sigma^{2} p\right)$}

Variansi korelasi populasi sesungguhnya di peroleh dengan cara mengurangkan varians korelasi dengan varians kesalahan pengambilan sampel, sehingga rumusnya adalah sebagai berikut:

$$
\sigma^{2} p=\sigma^{2} r-\sigma^{2} e
$$

Adapun hasil perhitungan diperoleh nilai varians korelasi populasi sebesar 0.0827. kemudian perhitungan standar deviasi yang telah dikoreksi diperoleh dari akar pangkat variansi korelasi populasi. Adapun SD korelasi diperoleh 0.288 .

\section{Interval Kepercayaan}

Interval kepercayaan diperoleh dengan membandingkan antara $\varnothing$ dengan SD yang telah dikoreksi. Adapun hasilnya adalah $=0.3135 / 0.288=1,090$. Angka ini terletak antara interval kepercayaan batas bawah dan interval kepercayaan batas atas. Hasil ini menunjukkan bahwa korelasi populasi studi adalah positif.

\section{Dampak kesalahan pengambilan sampel}

Reliabilitas korelasi studi dilakukan dengan membagi varians korelasi populasi dengan varians $r_{x y}$.

$$
\begin{gathered}
(1-\operatorname{Rel}(r)) \times 100 \% \\
\operatorname{Rel}(r)=\frac{\sigma^{2} p}{\sigma^{2} r}
\end{gathered}
$$

Hasil dari rumus di atas di peroleh nilai sebesar 0.999, sehingga persentase varians yang mengacu kesalahan pengambilan sampel adalah 0.1172 dibulatkan menjadi $0,12 \%$.

Selain melakukan koreksi kesalahan sample, dalam meta-analisis juga dilakukan pengkoreksian terhadap kesalahan pengukuran.

Berdasarkan hasil analisis artikel dapat diketahui bahwa tidak semua studi mencantumkan reliabilitas pengukuran baik untuk variabel independen maupun variabel dependen (residential satisfaction dengan housing characteristic). Dari 20 studi terdapat 13 studi yang tidak mencantumkan reliabilitas pengukuran untuk variabel independent; sedangkan reliabilitas pengukuran kepuasan menghuni sebagai variabel dependent tidak dicantumkan sebanyak 17 studi.

Koreksi kesalahan pengukuran dilakukan dengan langkah-langkah sebagai berikut:

\section{Mencari rerata gabungan dengan rumus $(\widetilde{A})$}

Rerata gabungan dihitung dengan menggunakan rumus berikut ini:

$$
\widetilde{A=} \operatorname{ave}(a) \operatorname{ave}(b)
$$

sehingga di peroleh nilai 0.7622 . 
Tabel 5. Lembar Kerja untuk Mencari Estimasi Kesalahan Pengukuran

\begin{tabular}{cccccccc}
\hline No & $\mathbf{N}$ & $\mathbf{r}_{\mathbf{X Y}}$ & $\mathbf{N X R X Y}$ & $\mathbf{r a a}$ & $\mathbf{( a )}$ & $\mathbf{r b b}$ & $\mathbf{( b )}$ \\
\hline $\mathbf{1}$ & 1018 & 0.458 & 466.244 & 0.000 & 0.000 & 0.000 & 0.000 \\
$\mathbf{2}$ & 300 & 0.067 & 20.1 & 0.000 & 0.000 & 0.000 & 0.000 \\
$\mathbf{3}$ & 43360 & 0.744 & 32259.84 & 0.000 & 0.000 & 0.000 & 0.000 \\
$\mathbf{4}$ & 250 & 1.000 & 250 & 0.000 & 0.000 & 0.000 & 0.000 \\
$\mathbf{5}$ & 168 & 0.075 & 12.6 & 0.000 & 0.000 & 0.000 & 0.000 \\
$\mathbf{6}$ & 4756 & 0.490 & 2330.44 & 0.000 & 0.000 & 0.000 & 0.000 \\
$\mathbf{7}$ & 638 & 0.009 & 5.742 & 0.920 & 0.959 & 0.000 & 0.000 \\
$\mathbf{8}$ & 492 & 0.133 & 65.436 & 0.744 & 0.863 & 0.000 & 0.000 \\
$\mathbf{9}$ & 50592 & 0.040 & 2023.68 & 0.820 & 0.906 & 0.680 & 0.825 \\
$\mathbf{1 0}$ & 55000 & 0.200 & 11000 & 0.000 & 0.000 & 0.000 & 0.000 \\
$\mathbf{1 1}$ & 5170 & 0.670 & 3463.9 & 0.000 & 0.000 & 0.000 & 0.000 \\
$\mathbf{1 2}$ & 452 & 0.182 & 82.264 & 0.890 & 0.943 & 0.000 & 0.000 \\
$\mathbf{1 3}$ & 1524 & 0.094 & 143.256 & 0.000 & 0.000 & 0.000 & 0.000 \\
$\mathbf{1 4}$ & 2164 & 0.046 & 99.544 & 0.000 & 0.000 & 0.000 & 0.000 \\
$\mathbf{1 5}$ & 300 & 0.077 & 23.1 & 0.840 & 0.917 & 0.790 & 0.889 \\
$\mathbf{1 6}$ & 267 & 0.009 & 2.403 & 0.000 & 0.000 & 0.000 & 0.000 \\
$\mathbf{1 7}$ & 80 & 0.495 & 39.6 & 0.650 & 0.806 & 0.000 & 0.000 \\
$\mathbf{1 8}$ & 107 & 0.269 & 28.783 & 0.730 & 0.854 & 0.720 & 0.849 \\
$\mathbf{1 9}$ & 401 & 0.088 & 35.288 & 0.000 & 0.000 & 0.000 & 0.000 \\
$\mathbf{2 0}$ & 562 & 0.346 & 194.452 & 0.000 & 0.000 & 0.000 & 0.000 \\
Total & 167601 & 5.492 & 52546.67 & 5.594 & 6.248 & 2.190 & 2.562 \\
rerata & 8380.05 & 0.2746 & 0.313522 & & 0.893 & & 0.854 \\
STD & 17946.14 & & & & 0.054 & & 0.032 \\
\hline
\end{tabular}

Sumber: Hasil analisis, 2015

Mencari korelasi populasi setelah dikoreksi oleh kesalahan pengukuran

Perhitungan korelasi populasi yang dikoreksi berdasarkan kesalahan pengukuran dihitung dengan rumus berikut:

$$
p=\frac{\check{r}}{\tilde{A}}
$$

Jadi korelasi populasi setelah dikoreksi relibilitasnya pada variable independen dan dependen sebesar 0.4113 .

Mencari jumlah koefisien kuadrat variasi.

Koefisien kuadrat variasi dihitung dengan penggunaan rumus sebagai berikut:

$$
V=\frac{S D^{2}(a)}{a v e^{2}(a)}+\frac{S D^{2}(b)}{a v e^{2} b}
$$

Sehingga di peroleh hasil 0.005
Varians yang mengacu variasi $\operatorname{artifak}\left(\sigma_{2}^{2}\right)$

variasi yang mengacu artifak dihitung dengan menggunakan rumus:

$$
\sigma^{22}=p^{2} \cdot \widetilde{A}^{2} \cdot V
$$

Sehingga di peroleh nilai sebesar 0.0000025 .

\section{Varians korelasi sesungguhnya (var} (p))

Variansi korelasi populasi yang sesungguhnya dihitung dengan menggunakan rumus:

$$
\operatorname{var}(p)=\frac{\sigma^{2} p-\left(p^{2} \cdot \widetilde{A}^{2} \cdot V\right)}{\tilde{A}^{2}}
$$

Sehingga diperoleh nilai 0.1423 , dengan nilai standar deviasi sebesar 0.377 .

\section{Dampak variasi reliabilitas}

Hasilnya $=0.00304 \%$. Dengan demikian, dapat dinyatakan bahwa 
variabilitas akibat kesalahan pengukuran memiliki peran sebesar $0.00304 \%$.

\section{Diskusi}

Studi meta-analisis ini menemukan bahwa korelasi populasi yang sesungguhnya setelah dikoreksi oleh kesalahan pengukuran sebesar 0,314. Varians kesalahan pengambilan sampel $\left(\sigma^{2} \mathrm{e}\right)$ sebesar 0,000097 , dengan standar variasi sebesar 0,288 , dan masuk dalam rentang interval kepercayaan 95\%, dimana nilai tersebut masuk dalam daerah batas interval yang diterima.

Koefisien korelasi populasi setelah dilakukan koreksi kesalahan pengukuran sebesar 0,005 , korelasi populasi sesuangguhnya diestimasi sebesar 0,4113 dan standar deviasi sebesar 0,377. Dengan menggunakan interval kepercayaan sebesar $95 \%$ maka korelasi tersebut masih dalam batas yang diterima. Kesimpulan dari perhitungan ini adalah ada hubungan yang positif antara karakteristik rumah dengan kepuasan penghuni dengan dampak variasi reliabilitas sebesar $0,00304 \%$.

Berdasarkan kesalahan dalam pengambilan sampel dan kesalahan pengukuran, maka hipotesis penelitian diterima, yaitu terdapat korelasi positif antara karakteristik rumah dengan kepuasan menghuni.

Hassanain (2008) mengkaji derajat kepuasan dari dua aspek yakni aspek teknis dan fungsional yang berkelanjutan pada fasilitas tempat tinggal. Salleh (2008) dan Mohit (2010) menjelaskan kepuasan menghuni merupakan suatu unit fitur tempat tinggal, fasilitas yang mendukung tempat tinggal, dan relasi pertetanggaan. Lebih jauh, Gifford
(2002) menerangkan kepuasan menghuni bukan hanya tergantung pada latar belakang fase hidup, social, budaya, situasi keuangan, dan harapan, namun juga pada karakteristik arsitektural dari bangunan atau tempat tinggal tersebut.

Faktor diatas oleh Khozaei dkk (2010) dikategorikan sebagai kategori social dan fisik. Kategori fisik mengacu pada karakteristik fisik bangunan atau tempat tinggal dan yang melingkupinya. Sedangkan kategori social lebih mengacu pada karakteristik penghuni yang melibatkan sensasi dan persepsi pada lingkungan.

Mengacu pada faktor fisik, Mohit (2010) menjelaskan dalam studi empirisnya, bahwa kepuasan penghuni berasosiasi dengan peningkatan dalam mengontrol keamanan, desain tempat tinggal dan privasi (Day, 2000); ukuran bangunan dan lama menempati (VeraToscano \& Ateca-Amestoy, 2008) ; adaptasi dan fleksibilitas dalam menggunakan suatu ruangan (Altas \& Ozsoy, 1998); dan kepuasan menggunakan fasilitas lingkungan (Berkoz \& Kellekci, 2009).

Sirmans, Mac Donald, Macpherson, dan Zieth (2006) menerangkan hasil kajian meta-analisisnya tentang 9 karakteristik rumah pada keluarga tunggal seperti ukuran luas, ukuran lot (kavling), usia, ruang tidur, kamar mandi, garasi, kolam renang, alat pemadam kebakaran, dan pendingin ruangan. Hasil ini memperlihatkan nilai koefisien yang tinggi dan berbeda-beda sesuai dengan lokasi geografis, waktu, tipe data, dan spesifikasi model bangunan.

Galster dan Hesser (1981) menerangkan bahwa kepuasan menghuni memiliki garis lurus dengan 
aspirasi penghuninya terhadap huniannya, sehingga kepuasan tersebut dapat diukur. Oleh sebab itu jika individu berada dalam level tidak puas sebagai penghuni, maka ia akan cenderung melakukan beberapa cara (Brown \& Moore, 1970; Michelson, 1977; Galster \& Hesser, 1981; Permentier dkk, 2011) diantaranya:

1) Berpindah tempat tinggal

2) Merubah kondisi hunian

3) Merubah kognisi

Banyaknya disiplin ilmu yang mengkaji tentang tempat tinggal telah membuat perkembangan yang luar biasa sebagai latar belakang dalam melakukan evaluasi pasca huni. Dari banyaknya kajian arsitektural, para ilmuan sependapat bahwa terbentuknya perilaku tertentu pada individu yang disebabkan karena tempat tinggal tak lepas dari bermulanya sensasi yang dirasakan dirinya terhadap tempat tinggal tersebut (sense of place). Kehadiran sense of place ini dapat menunjukkan pada kita tingkat kepuasan terhadap suatu tempat seperti rumah, sekolah, maupun kota.

Twigger dan Uzzell (1996) memberikan satu consensus utama bahwa individu akan memberikan makna, nilai, dan rasa dari setting suatu tempat. Menurut Jorgensen dan Stedman (2001) terdapat tiga konsep utama dari sense of place untuk memahami hubungan antara suatu tempat atau lokasi dengan individu, sehingga yang berlokasi di tempat tersebut dapat memberikan makna, nilai dan rasa. Ketiga konsep itu adalah:

a) Identitas

Identitas suatu tempat (place identity) memiliki fokus pada konsep diri penghuni dan tempat itu sendiri. Fokus ini memberikan kesempatan pada individu untuk mengembangkan dan menterjemahkan kebermaknaan dirinya dan kebersatuan pada suatu tempat (Cuba \& Hummon, 1993).

Karena berfokus pada konsep diri, maka identitas tempat ini sangat melibatkan proses kognitif individu untuk pengidentifikasiannya. Identitas untuk relasi pertetanggaan dan suatu kota seringkali menjadi cerminan untuk melihat karakteristik sampai kualitas area tersebut. Sehingga kita dapat melihat ketika individu mengidentitaskan suatu tempat, maka ia akan melibatkan level rasa kepemilikian dan komitmennya terhadap tempat tersebut.

\section{b) Kelekatan}

Kelekatan terhadap suatu tempat dapat didefinisikan sebagai kebersatuan faktor afektif antara individu dengan tempat ia berada (Tuan, 1977). Secara umum, kelekatan pada suatu tempat merupakan hasil interaksi individu yang menempati lingkungan (tempat) tersebut dengan orang sekitarnya (Trentelman, 2009 ; Altman, 1992).

Kelekatan inilah yang akan memperlihatkan keterikatan emosional level individu dan komunitasnya. Pada level individu, kelekatan memiliki asosiasi pada bentuk perilaku, kognitif, serta pengalaman yang melibatkan emosi pada lingkungan ia berada. Sedangkan pada level komunitas, kelekatan mengacu pada kebersatuan rasa menjadi bagian dari suatu kelompok (komunitas) dan tetangga. Kelekatan ini dapat mengembangkan identitas diri dan kelompok karena akan memunculkan rasa aman, nyaman. Kasarda dan Janowitz (1974) memberikan tiga indikator utama dalam kelekatan komunitas pada individu, yakni (1) rasa memiliki 
terhadap area (being "at home"); (2) tertarik untuk mencari tahu apa yang terjadi di lingkungan tinggalnya; dan (3) memohon untuk dimaafkan jika pindah dari lingkungan tersebut. Guest dan Lee (1983) menunjukkan dua dimensi yang terdapat dalam kelekatan komunitas, yaitu (1) sentimen komunitas, ini mengacu pada perasaan (emosional) atau kondisi psikologis pada suatu tempat yang merefleksikan seberapa rindunya individu tersebut jika berpindah ke tempat yang lain; (2) evaluasi komunitas, pada dimensi ini individu dapat menilai tingkat kepuasan secara menyeluruh tentang tempat tinggalnya. Lalli (1992) menguatkan pendapat diatas. Menurutnya, konsep kelekatan pada suatu tempat adalah perasaan memiliki (sense of belonging), yang mana ini mempunyai hubungan erat dengan sensasi individu terhadap suatu tempat, sehingga kelekatan berisi hal-hal yang berkaitan dengan persaudaraan, keberlangsungan, dan komitmen terhadap suatu tempat

\section{c) Ketergantungan}

Ketergantungan pada suatu tempat dapat digambarkan dengan individu memiliki keterkaitan untuk memperoleh tujuan (goal) ataupun mengembangkan kemampuan dirinya yang disebabkan karena tempat ia tinggal. Hal ini memberikan dampak pada self-esteem individu maupun kelompok, efikasi diri, dan kemampuan dalam mengelola atau mengontrol lingkungannya, sehingga yang bertempat tinggal di wilayah tersebut merasa sejahtera.

Studi lainnya yang mencoba mengkaji kepuasan penghuni, seperti Schutt dkk (1997) menggunakan skala Lehman untuk menguji hubungan antara memilih hunian dengan kepuasannya. Ia menganjurkan, jika ingin melihat kepuasan penghuni sebaiknya mengkaji dari beragam dimensi.

Penggunaan skala Lehman dapat membantu untuk mengukur indikator subjektif dan objektif dari kualitas hidup dengan melihat dimensi hunian, pekerjaan, relasi, keluarga, dan legal domain. Untuk indikator tempat tinggal dilihat dari kualitas huniannya yang menyangkut infrastuktur yang tepat seperti kamar mandi, saluran pipa, saluran listrik dan sebagainya. Sedangkan untuk indikator subjektif seperti respon kepuasan pada relasi pertetanggaan maupun rasa aman.

\section{Kesimpulan}

Studi meta analisis ini menunjukkan bahwa elemen-elemen di sekitar tempat tinggal seperti tipe rumah, pencahayaan, saluran pembuangan, dan elemen fungsional serta teknis dari hunian memberikan pengaruh pada tingkat kepuasan penghuninya. Hal ini menunjukkan bahwa unsur karakteristik tempat tinggal berkorelasi positif dengan kepuasan menghuni.

Implikasi dari penelitian ini adalah faktor penentuan kebijakan dalam membangun tempat tinggal agar memenuhi kriteria elemen fungsional, elemen teknis, dan elemen perilakunya. Oleh sebab itu, selain faktor psikologis dari pengguna, maka karakteristik tempat tinggal juga menjadi acuan agar terciptanya kepuasan pada penghuni.

\section{Daftar Pustaka}

Adriaanse, C.C.M. (2007). Measuring residential satisfaction: a residential environmental satisfaction scale (RESS). Journal Housing Built Environment, Vol 22, 287-304. 
Altas, N.E. \& Ozsoy, A. (1998). Spatial adaptability and flexibility as parameters of user satisfaction for quality housing. Building and Environment, Vol.33, 315323.

Altman I., Low S M. (1992). Place attachment. New York, NY : Plenum.

Amerigo, M. \& Aragones, J. (1990). Residential satisfaction in council housing. Journal of Environmental Psychology, vol 10, 313-325.

Austin, D.M., Furr, L.A., Spine, M. (2002). The effect of neighborhood conditions on perception of safety. Journal of Criminal Justice. No.30, 417427.

Baiden, P., Arku, G., Luginaah, I. (2011). An assessment of residents housing satisfaction and coping in Accra, Ghana. Journal Public Health No.19, 29-37.

Berkoz, L., Turk, S.S.E. \& Kellekci, O.M.L. (2009). Environmental quality and user satisfaction in mass housing areas: the case of Istanbul. European Planning Studies, Vol.17, 161-174.

Bond, J. (1993). Ageing in society : An Introduction to Social Gerontology. London, UK: Sage.

Brown, L.A., \& Moore, E.G. (1970). The intra-urban migration process : a perspective .Geografiska Annaler Series BHuman Geography, 52,1-13.

Cho, S.H. Lee, T.K., Kim, J. T. (2010). Residents' satisfaction of indoor environmental quality in their old apartment homes. Indoor and Built Environment, Vol 20 (1), 16-25.
Cuba, L. \& Hummon, D. (1993). A place to call home: Identification with dwelling, community, and region. The Sosiological Quarterly. Vol 34. No 1. 111-131.

Day, L.L. (2000). Choosing a house the relationship between dwelling type, perception of privacy and residential satisfaction. Journal of Planning Education and Research, Vol. 19, 265-275.

Dekker, K., Vos, S.D., Musterd, S., Kempen, R. (2011). Residential satisfaction in housing estates in Europian cities: a multi-level research appoarch. Housing Studies, Vol.26, No. 4, 479-499.

Dinc, P., Ozbilen, E., Bilir, Mehmet B. (2013). A multi-dimensional for measuring residential satisfaction (rs) in mass housing projects. Indoor and Built Environment. Vol 0 (0), 1-17.

Galster, G. C \& Hesser, G. W. (1981). Residential satisfaction : compositional and contextual correlates. Environment and Behavior, 13. 735-758.

Gifford, R. (2002). Environmental psychology. Principles and practice $\left(3^{\text {rd }}\right.$ ed). Victoria, Canada: Optimal Books.

Golant, S.M. (1984). A place to grow old: The meaning of environment in old age. New York: Colombia University Press.

Gomez-Jacinto, L. \& Hombrados Mendieta, I. (2002). Multiple effects of community and household crowding. Journal of Environmental Psychology, 22, 233-246.

Guest A.M., Lee, B. A. (1983). Sentiment and evaluation as ecological variables. Social Perspect. 26 (2): 159-184. 
Hassanain, M.A. (2008). On the performance evaluation of sustainable student housing facilities. Journal Facilities Manage.,6: 212-225.

Ibem, E., O., Amole, D. (2013). Satisfaction with life in public housing in Ogun State, Nigeria: A research note. Journal Happiness Studies. DOI 10.1007/s10902-013-9438-7.

Jagun, A., Brown, D., Milburn N., Gary, L. (1990). Residential satisfaction and socioeconomic and housing characteristics of urban black adults. Journal of Black Studies, Vol.21, No 1, pp 40-51.

James, R. (2007). Multifamily housing characteristics and tenant satisfaction. Journal of Performance of Constructed Facilities, pp 472-480.

James, R. (2008). Impact of subsidized rental housing characteristics on metropolitan residental ratisfaction. Journal of Urban Planning and Development, DOI. 10.1061/(ASCE)0733488(2008)134:4(166), 166-172.

James, R. (2008). Residential satisfaction of elderly tenants in apartment housing. Soc Indic Res No. 89, 421-437.

Jorgensen, B.S. \& Stedman R.C. (2001). Sense of place as an attitude: Lakeshore owners attitudes toward their properties. Journal

Environmental

Psychology.21:233-248.

Kaplan, R. (1985). Nature at the doorstep: Residential satisfaction and the nearby environment. Journal of Architectural and Planning Research, 2, 115-127.
Kaplan, S \& Kaplan, R. (2003). Health supportive environments, and the reasonable person model. American Journal of Public Health, Vol.93, No.9, 14841489.

Kasarda, J.D., Janowitz, M. (1974). Community attachment in mass society. Am Soc Rev. 39: 229328.

Kellekci, O.L., Berkoz, L. (2006). Mass housing: User satisfaction in housing and its environment in Istanbul, Turkey. European Journal of Housing Policy. Vol.6, No.1, 77-99.

Khozaei, F., Hassan, A.S. \& Khozaei, Z. (2010). Understanding students satisfaction with hostel and sense of attachment to place, case study at University Sains Malaysia. American Journal of Engineering and Applied Sciences. Vol.3. 516520.

Kutty, N.K. (1999). Determinants of structural adequacy of dwelling. Journal of Housing Research. Vol. 10, No.1, pp.27-43.

Lalli, M. (1992). Urban-related identity. Journal Environment Psychology. 21: 285-303.

Li-Hin, L. (2009). Community attachment and housing choice in Hong Kong. Property Management, Vol 27, No.1, 4257.

Lu, M. (1999). Determinants of residential satisfaction: ordered logit vs. regression models. Growth and Change, Vol 30, 264-287.

Marx, K.A., Burke, K.L., Graines, J., Resnick, B., Parrish, J. (2011). Satisfaction with your new home: advantages and disadvantages to living in a 
CCRC. Senior Housing \& Care Journal, Vol 19 (1), 83-96.

Mc Cray, J.W. \&, Day S.S. (1977). Housing values, aspirating and satisfactions as indicators of housing need. Home Economics Research Journal. 5. 244-254.

Michelson, W. (1997). Environmental choice, human behavior, and residential satisfaction. New York: Oxford University Press.

Mohit, M.A,. Ibrahim, M.Y.R. Rashid. (2010). Assessment of residential satisfaction in newly designed public low-cost housing in Kuala Lumpur, Malaysia. Habitat Int. 34. 1827.

Mohit, M.A., Nazyddah, N. (2011). Social housing programme of Selangor Zakat Board of Malaysia and housing satisfaction. Journal Housing and The Built Environment, Vol 26, 143-164.

Morris, E.W., Crull, S.R. \& Winter, M. (1978). Housing norms, housing satisfaction and the propensity to move. Journal of Marriage and The Family, vol.38 No.2, 309-320

Mowen, J.C. (1995). Consumer behavior. $5^{\text {th }}$ ed. Englewood Cliffs. NJ: Prentice Hall.

Muhammad, Z., Rostam, K., Yussof, Y. (2010). Residential satisfaction with housing in the Malaysian context. The International Journal of Interdisciplinary Social Sciences. Vol, 5, No. 2, 299395.

Nelson, G., Hall, G. B., Bowers, R. W. (1998). The relationship between housing characteristics, emotional well-being and the personal empowerment of psychiatric consumer/survivors.
Community Mental Health

Journal, Vol.34. No., 57-69.

Permentier, M., Bolt, G. \& Van Ham, M. (2011). Determinants of neighborhood satisfaction and perception of neighborhood reputation. Urban Studies, 48, 977-996.

Phillips, D.R, Siu. O.L., Yeh. A., Cheng, K.H.C. (2004). Factors influencing older persons residential satisfaction in big and densely populated cities in asia : a case study in Hong Kong. Aging International. Vol.29, No.1, 46-70.

Rent, G.S., \& Rent, C.S. (1973). Lowincome housing: factors related to residential satisfaction. Environment and Behavior, Vol.10, 459-488.

Rodgers, W. (1980). Residential satisfaction in relationship to size of place. Social Psychology Quarterly, Vol.43, No.4, 436441.

Rogers, E.C. \& Nikkel, S.R. (1979). The housing satisfaction of large urban families. Housing and Society, Vol 6, 73-87.

Salleh, A.G. (2008). Neighborhood factors in private low-cost housing in Malaysia. Habitat Int. 32. 485-493.

Sinai, I. (2001). Moving or improving: Housing adjustment choice in Kumasi, Ghana. Housing Studies, Vol.16, No.1, 97-114.

Sirmans, G.S., MacDonald, L., Macpherson, D.A., Zietz, E.N. (2006). The value of housing characteristics: A meta analysis. Journal Real Estate Finan Econ 33, $215-240$.

Stewart, K.K., \& C. McKown. (1997). Determinats of housing satisfaction in rural low-income 
families. Housing Educators

Journal. 4. 33-39.

Trentelman, C.K. (2009). Place attachment and community attachment: A primer grounded in the lived experience of a community sociologist. Soc Nat Resour.;22 : 191-210.

Tsemberis, S., Rogers, E. S., Rodis, E., Dushuttle, P., Skryha, V. (2003). Housing satisfaction for person with psychiatric disabilities. Journal of Community Psychology, Vol.31, No.6, 581-590.

Tuan, Y. (1977). Space and place : The perspective of experience. Minneapolis, MN: University of Minnesota Press.

Twigger, R. \& Uzzell, D.L. (1996). Place and identity processes. Journal Environmental Psychology. 16: 205-220.

Vera, T. \& Ateca, A. (2008) . The relevance of social interactions on housing satisfaction. Social indicators research. Vol.86. 257-274. 